\title{
Beyond Fish Oil Supplementation: The Effects of Alternative Plant Sources of Omega-3 Polyunsaturated Fatty Acids upon Lipid Indexes and Cardiometabolic Biomarkers-An Overview
}

\author{
Heitor O. Santos ${ }^{1, *}$, James C. Price ${ }^{2}$ and Allain A. Bueno ${ }^{2}(\mathbb{C}$ \\ 1 School of Medicine, Federal University of Uberlandia (UFU), Uberlandia 38408-100, Brazil \\ 2 College of Health, Life and Environmental Sciences, University of Worcester, Worcester WR2 6AJ, UK; \\ prij2_16@uni.worc.ac.uk (J.C.P.); a.bueno@worc.ac.uk (A.A.B.) \\ * Correspondence: heitoroliveirasantos@gmail.com
}

Received: 27 September 2020; Accepted: 14 October 2020; Published: 16 October 2020

\begin{abstract}
Cardiovascular diseases remain a global challenge, and lipid-associated biomarkers can predict cardiovascular events. Extensive research on cardiovascular benefits of omega-3 polyunsaturated fatty acids (n3-PUFAs) is geared towards fish oil supplementation and fish-rich diets. Nevertheless, vegetarianism and veganism are becoming more popular across all segments of society, due to reasons as varied as personal, ethical and religious values, individual preferences and environment-related principles, amongst others. Due to the essentiality of PUFAs, plant sources of n3-PUFAs warrant further consideration. In this review, we have critically appraised the efficacy of plant-derived n3-PUFAs from foodstuffs and supplements upon lipid profile and selected cardiometabolic markers. Walnuts and flaxseed are the most common plant sources of n3-PUFAs, mainly alpha-linolenic acid (ALA), and feature the strongest scientific rationale for applicability into clinical practice. Furthermore, walnuts and flaxseed are sources of fibre, potassium, magnesium, and non-essential substances, including polyphenols and sterols, which in conjunction are known to ameliorate cardiovascular metabolism. ALA levels in rapeseed and soybean oils are only slight when compared to flaxseed oil. Spirulina and Chlorella, biomasses of cyanobacteria and green algae, are important sources of n3-PUFAs; however, their benefits upon cardiometabolic markers are plausibly driven by their antioxidant potential combined with their n3-PUFA content. In humans, ALA is not sufficiently bioconverted into eicosapentaenoic and docosahexaenoic acids. However, evidence suggests that plant sources of ALA are associated with favourable cardiometabolic status. ALA supplementation, or increased consumption of ALA-rich foodstuffs, combined with reduced omega-6 (n6) PUFAs intake, could improve the n3/n6 ratio and improve cardiometabolic and lipid profile.
\end{abstract}

Keywords: alpha-linolenic acid; flaxseed; lipids; omega-3; walnuts

\section{Introduction}

Cardiovascular diseases remain a major Public Health concern, with lipid-associated biomarkers being trusted predictors of major cardiovascular events [1,2]. Added to the pharmacological strategies and conscious effort to improve the patients' lifestyle by adequate nutrition and physical activity, nutraceutical strategies which include certain supplements, herbal extracts and functional foods, may be a helpful complementary approach for individuals with cardiovascular disease and dyslipidaemia [3-9].

The dietary replacement of saturated fats for polyunsaturated fatty acids (PUFAs) has shown beneficial effects upon lipid profile [10], as well as long-term protective benefits against 
major cardiovascular events and associated clinical complications [11,12]. For decades, omega-3 polyunsaturated fatty acids (n3-PUFAs) from either marine sources or fish oil (FO) supplementation were broadly referred to in cardiology guidelines [13-15]. For example, amongst several clinical investigations, Sagara et al. in 2011 showed that $2 \mathrm{~g}$ of DHA daily for five weeks improved blood pressure and lipid profile in a sample population of 38 middle-age men with hypertension and hypercholesterolaemia [16].

On the other hand, however, Manger et al. in 2010 did not find a significant trend in reduced risk of coronary events with increased consumption of n3-PUFAs from fish and fish supplements. Nonetheless, Manger argues that their sample population had a high intake of n3-PUA to begin with, and possibly the lack of association could have been attributed to a ceiling effect of n3-PUFAs [17]. Interestingly, a robust meta-analysis published in 2018, which included 79 Randomized Control Trials (RCTs) and a total of 112,059 participants, showed that n3-PUFAs supplementation actually did not show significantly greater efficacy on reducing the occurrence of cardiovascular events [18]. Such results must be interpreted carefully due to factors such as methodology employed, varied sample population investigated, other factors beyond the scope of the study, and a potential risk for bias. At the same time, it has also been demonstrated that plant sources of n3-PUFAs have shown some potential against cardiovascular events and dyslipidaemia [18].

The findings on fish consumption and FO supplementation upon cardiovascular health do not disregard the merit of investigating the usefulness of plant-derived n3-PUFAs in clinical practice. Studies on the potential efficacy of plant-derived n3-PUFAs become further justified as dramatic reductions of fish stocks have been reported in the North Atlantic Ocean and Mediterranean Sea [19,20]. In the present review, we have critically appraised the efficacy of plant-derived n3-PUFAs from foodstuffs, as well as its supplementation, upon the modulation of lipid profile and selected cardiometabolic markers. More specifically, we searched for the effects of chia seeds, flaxseeds, walnuts, as well as Spirulina and Chlorella. As those foodstuffs are gaining more popularity, a phenomenon possibly attributed to the increased awareness of environmental issues related to overfishing, combined with the increasing trend towards veganism, vegetarianism and flexitarianism across all segments of society, it is of greatest interest to clarify the clinical potential of plant sources of n3-PUFAs.

\section{Methods}

We employed the electronic databases Pubmed/Medline and Google Scholar to identify relevant publications. Randomised Controlled Trials (RCTs) written in English were the chosen sources of results as a means of translating current research findings into clinical practice. Preferred Reporting Items for Systematic Reviews and Meta-Analyses (PRISMA) guidelines [21] were used to evaluate and select the RCTs.

Limited to RCTs, we searched for plant sources of ALA by using the following combinations of Medical Subject Heading (MeSH) keywords: ("Chia Seeds" OR "Flaxseeds" OR "Hemp Seeds" OR "Walnuts" OR "Seaweeds" OR "Spirulina" OR "Chlorella") AND ("LDL-C" OR "Low-Density Lipoprotein Cholesterol" OR "Total Cholesterol" OR "Triglycerides" OR "HDL-C" OR "Low-Density Lipoprotein Cholesterol" OR "Blood Pressure" OR "Cardiovascular Disease" OR "Cardiometabolic Risk" OR "Inflammatory Biomarkers" OR "Proinflammatory Cytokines"). The period covered in the search included inception to August 2020. Summary findings from the selected papers are presented in Supplementary Tables S1-S3. After perusal of such findings, we discussed key aspects and manually expanded the review by selecting further articles that have investigated nutrition facts, mechanisms of action and clinical applications.

As the number and robustness of clinical studies that have investigated the metabolic effects of plant-derived n3-PUFAs are only a fraction of those that employed FO, we have also summarized in Supplementary Table S4 the outcomes of 38 selected FO supplementation studies identified using the key terms listed above and published in the last five years, with a combined sample population of 
4136 individuals. The evidence gathered confirms that whilst some studies did show improvements in metabolic biomarkers after FO supplementation, some others did not.

\section{Metabolic Pathways}

\subsection{Conversion of ALA in Humans}

Not only the insufficient intake of dietary n3-PUFAs, but also the inefficient elongation and desaturation of ALA to eicosapentaenoic acid (EPA) and docosahexaenoic acid (DHA) in humans, result in low $n 3$ long chain-PUFA content in blood and other peripheral tissues [22,23]. Accordingly, North America, Central and South America, and Africa, are geographical examples where EPA and DHA concentrations are endemically low [24]. More specifically, the intake of n3-PUFAs in the average USA population is low or very low [14].

Approximately only $5 \%$ of ALA is converted to EPA whilst less than $0.5 \%$ is converted to DHA in humans, although mammals have the essential enzymes used in this pathway [25-27]. A proof-of-concept study published in 2010 showed in newborn infants that only approximately $0.04 \%$ of ALA administered was elongated and desaturated to circulating EPA, whilst the subsequent conversion of EPA to DHA was comparatively more efficient [28]. The very low ALA to EPA bioconversion ratio identified in that study does not account for the EPA that was actually incorporated into solid tissues, but it does confirm the suggestion that even large amounts of dietary ALA will probably have negligible effects on plasma DHA levels [27].

Moreover, the conversion of ALA to EPA and subsequently DHA appears to be more efficient in women than in men, a phenomenon that could probably be explained by a possibly advantageous action of oestrogens in protecting the mother and the lactating child. Gender difference is a factor to be considered before making dietary recommendations for n3-PUFAs intake [25].

\section{2. n3-PUFAs Versus n6-PUFAs}

The inefficient bioconversion of ALA to EPA and DHA becomes more evident when considering that n3 and omega-6 (n6) PUFAs, although in much different concentrations in the typical westernized diet, compete almost equally for the same enzymatic pathway that elongates and desaturates the precursors ALA and linoleic acid (LA) to EPA and arachidonic acid (AA), respectively [29]. On the other hand however, potential roles for ALA in human health that may be independent of its bioconversion onto DHA have been proposed [27].

Experimental evidence alludes to a slower enzymatic metabolism of n3-PUFAs in relation to n6-PUFAs [30]. Therefore, focus on ALA intake is paramount for human health, but similarly important is the adequate intake of LA, as not to imbalance the n6/n3 ratio. Typical westernized diets show abundance of meats and poultry alongside deep-fried foodstuffs, an important dietary characteristic that favours high LA intake.

As seen in Figure 1, dietary sources of n6-PUFAs lead to raised levels of AA, culminating in increased synthesis of pro-inflammatory eicosanoids. Dietary sources of n3-PUFAs, in turn, allow the synthesis of anti-inflammatory eicosanoids. Increased n3-PUFA concomitant to decreased n6-PUFA decreases the AA content in platelets, vascular endothelial cells and vascular wall macrophages, thus reducing AA-derived pro-inflammatory mediators [31]. Cyclooxygenases (COX) and lipoxygenases (LOX) convert AA to prostaglandin E2, thromboxane A2, prostaglandin I2 and leukotriene B4, amongst other pro-inflammatory eicosanoids, whilst the same enzymatic pathways convert EPA to prostaglandin E3, thromboxane A3, prostaglandin I3 and leukotriene B5, amongst other anti-inflammatory eicosanoids [32-34]. 


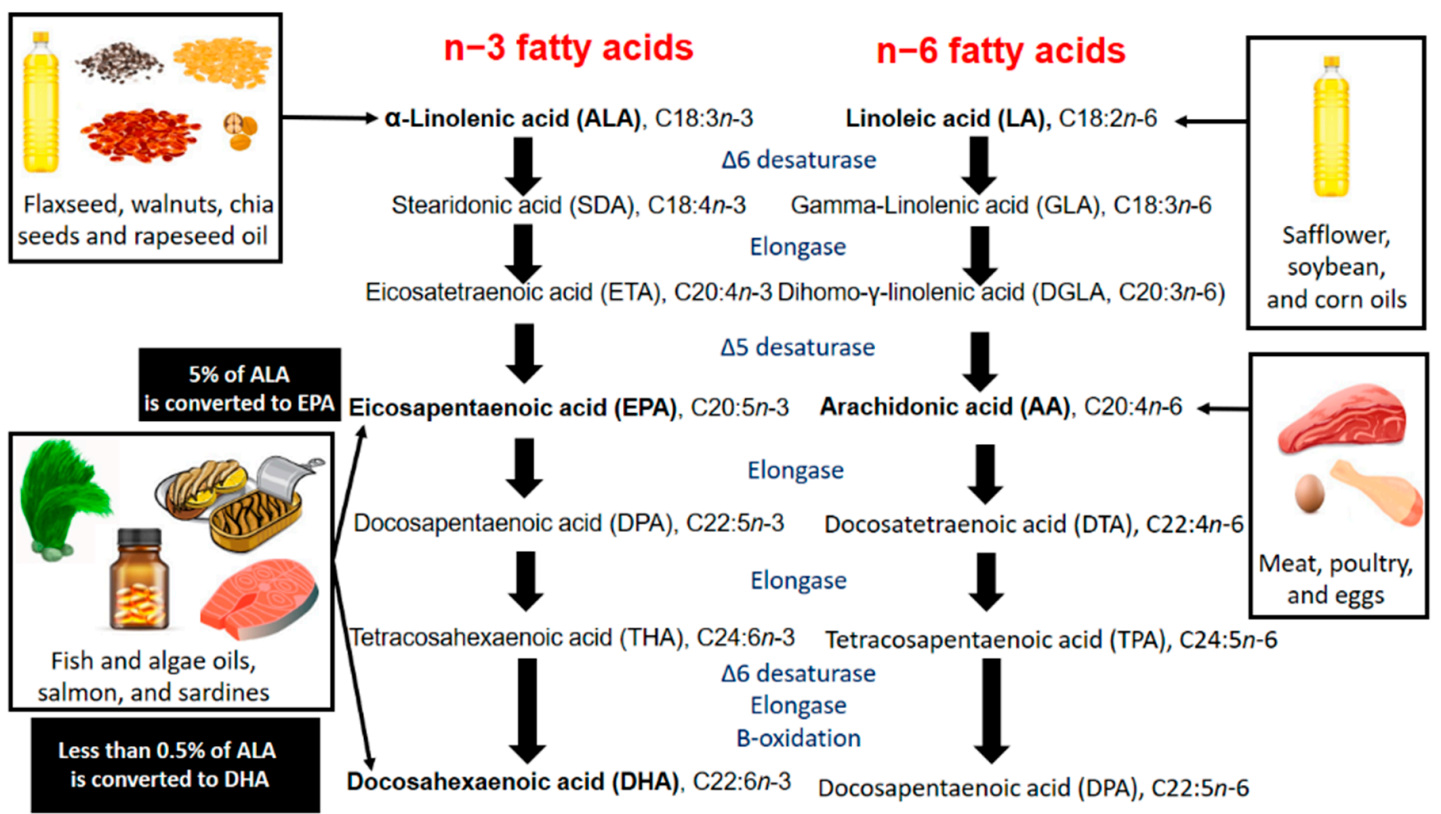

Figure 1. Whilst the main dietary sources of the n3-PUFAs EPA and DHA are fatty fish (e.g., salmon and sardines) and algae, the n3 precursor ALA is found mainly in walnuts, chia seeds, flaxseeds, and rapeseed oil. Likewise, meat, poultry and eggs are important sources of the n6-PUFAs AA, and its n6 precursor LA is found mainly in safflower, sunflower, soybean and corn oils [35-37]. ALA and LA are converted by desaturases and elongases to EPA and AA, respectively, and subsequently converted in a series of complex enzymatic reactions to the longer forms DHA and n6-docosapentaenoic (n6-DPA), respectively $[38,39]$.

\subsection{Cardiometabolic Pathways}

It has been observed in vitro that ALA is associated with decreased expression levels of vascular cell adhesion molecule-1 (VCAM-1), interleukin 6 (IL-6), proliferating cell nuclear antigen (PCNA), macrophage marker M3/84 (mac-3) and stearoyl-CoA desaturase-1 (SCD-1) [40]. Indirect effects of ALA upon cardiometabolic pathways have also been observed; ALA bioconversion to DPA is associated with decreased expression levels of COX-1, COX-2 and tumour necrosis factor-alpha $(\mathrm{TNF}-\alpha)$, whilst its bioconversion to EPA and DHA is associated with decreased expression levels of peroxisome proliferator-activated receptor gamma (PPAR- $\gamma$ ) [40].

Given that such results have also been identified in aortic tissue [41], it is reasonable to speculate that the positive effects of ALA are driven by attenuation of inflammation, cell proliferation and oxidation [40]. In a more optimistic, long-term speculative scenario, such ALA-induced effects could retard the progression, or even promote an amelioration, of the atherosclerotic state.

ALA administration to primary cultured endothelial cells induced inhibitions of NAD-dependent deacetylase sirtuin-3 (SIRT3) reduction, superoxide dismutase 2 (SOD2) hyperacetylation, and mitochondrial reactive oxygen species (ROS) overproduction, alongside restoration of autophagic flux under damage induced by treatment with angiotensin II plus TNF $\alpha$ [42,43]. Such effects, apparently attributed to ALA, are in line with mitigation of endothelial dysfunction and experimental hypertension [42].

It is known that n3-PUFAs have the capacity to decrease liver triglyceride (TG) synthesis by competitive inhibition of 1,2 diglyceride acyltransferase (DAT), at the same time suppressing the activity of sterol regulatory element-binding protein 1c (SREBP-1c) - A protein that regulates the expression of genes involved in fatty acid and TG synthesis-and also to increase $\beta$-oxidation in adipose tissue [44,45]. Regarding the latter, the high affinity of n3-PUFAs for peroxisome proliferator-activated receptor alpha (PPAR- $\alpha$ ) leads to a greater synthesis of enzymes involved in lipid catabolism, thus favoring not only fatty acid $\beta$-oxidation in peripheral tissues but also catabolism of circulating TG in chylomicrons and 
very low-density lipoprotein cholesterol (VLDL-C) [44,46,47]. Moreover, substrates for TG synthesis are also decreased by reduced transport of non-esterified fatty acids to hepatocytes, consequently reducing VLDL-C synthesis [44,48]. Nonetheless, as the majority of the cardiometabolic pathways so far elucidated are based on experimental data [40-43], a more thorough, critical and applied appraisal of the effects of ALA is needed before any general conclusions can be made.

\section{Alternative Plant Sources of n3-PUFAs}

\subsection{Nuts and Seeds}

\subsubsection{Nutrition Facts}

Nuts and seeds are important sources of ALA and also micronutrients, polyphenolic compounds, sterols and fibres, which are protective elements against the exacerbation of chronic diseases [49-51]. For instance, nuts and seeds that are sources of ALA also contain a considerable amount of calcium, magnesium, and potassium (Table 1), which are fundamental macrominerals for cardiovascular health, mainly in the management of hypertension [52-56]. Furthermore, nuts and seeds are a source of protein. Although at lower levels as compared to animal-derived protein in terms of needs for muscle hypertrophy, the consumption of nuts and seeds is inversely correlated with cardiovascular events and mortality, as demonstrated by recent studies $[57,58]$.

Table 1. Nutrition facts of ALA-containing seeds.

\begin{tabular}{|c|c|c|c|c|c|c|c|c|c|c|c|}
\hline $\begin{array}{c}\text { Food Item, } \\
\text { one Ounce } \\
/ \approx 28 \mathrm{~g} \\
{[\text { FDC ID] }}\end{array}$ & $\begin{array}{l}\text { Energy } \\
\text { (kcal) }\end{array}$ & $\begin{array}{l}\text { Protein } \\
\text { (g) }\end{array}$ & $\begin{array}{c}\text { Total Lipid } \\
\text { (g) }\end{array}$ & $\begin{array}{c}\text { Total Fiber } \\
\text { (g) }\end{array}$ & $\begin{array}{c}\mathrm{CHO} \\
(\mathrm{g})\end{array}$ & $\begin{array}{l}\mathrm{Ca} \\
(\mathrm{mg})\end{array}$ & $\begin{array}{c}\mathrm{Mg} \\
(\mathrm{mg})\end{array}$ & $\begin{array}{c}\mathrm{K} \\
(\mathrm{mg})\end{array}$ & $\begin{array}{c}\text { LA, 18:2, } \\
n-6 \\
\quad(g)\end{array}$ & $\begin{array}{c}\text { ALA, } \\
18: 3, \\
n-3 \\
(g)\end{array}$ & $\begin{array}{l}n-6 \\
/ n-3 \\
\text { Ratio }\end{array}$ \\
\hline $\begin{array}{c}\text { Chia seeds } \\
\text { [170554] }\end{array}$ & 136 & 4.63 & 8.60 & 9.75 & 11.79 & 176.68 & 93.8 & 113.96 & 1.63 & 4.99 & 0.32 \\
\hline $\begin{array}{c}\text { Hemp seed } \\
{[170148]}\end{array}$ & 155 & 8.83 & 13.65 & 1.12 & 2.42 & 19.6 & 196 & 366 & 7.68 & 2.80 & 2.74 \\
\hline $\begin{array}{l}\text { Flaxseed } \\
{[169414]}\end{array}$ & 150 & 5.12 & 11.80 & 7.64 & 8.08 & 71.4 & 109.76 & 227.64 & 1.65 & 6.38 & 0.25 \\
\hline $\begin{array}{l}\text { Walnuts } \\
\text { [784410] }\end{array}$ & 183.12 & 4.26 & 18.25 & 1.9 & 3.83 & 27.44 & 44.24 & 123.48 & 10.8 & 2.54 & 4.25 \\
\hline
\end{tabular}

Adapted from the United States Department of Agriculture (USDA) database [59]. ALA, alpha-linolenic acid; CA, calcium; CHO, carbohydrate by difference; FDC, FoodData Central; K, potassium; LA, linoleic acid; Mg, Magnesium.

Regarding the ALA content of nuts and seeds, one ounce (28 g) of flaxseed, chia seeds, hemp seed or walnuts exceeds the Adequate Intake (AIs) for ALA, which is $1.1 \mathrm{~g} /$ day for women and $1.6 \mathrm{~g} / \mathrm{day}$ for men, and $1.4 \mathrm{~g} /$ day and $1.3 \mathrm{~g} /$ day during pregnancy and lactation, respectively [59,60]. In one ounce, there are $6.38 \mathrm{~g}$ (398\% and 580\% of AIs for men and women) of ALA in flaxseed, $4.99 \mathrm{~g}$ (175\% and $254 \%$ of AIs for men and women) in chia seeds, $2.80 \mathrm{~g}$ (312\% and $453 \%$ of AIs for men and women) in hemp seed, $2.54 \mathrm{~g}$ (159\% and 230\% of AIs for men and women) in walnuts (Table 1).

\subsubsection{Walnuts}

Walnuts are an important source of ALA [61,62]. A 2-years follow-up study recruited 236 elderly subjects, segregated into two groups: a control group without nut consumption, and an intervention group in which $15 \%$ of the approximate daily energy intake consisted of walnuts, at approximately 30-60 g/day of walnuts [63]. The researchers found a reduction of $8.5 \mathrm{mmHg}$ in the systolic blood pressure, whose baseline levels were $>125 \mathrm{mmHg}$; however, no changes were observed in diastolic blood pressure. In the same study, the participants who consumed walnuts required lower dosages of antihypertensive drugs as compared to the control participants. The blood pressure of all participants in that study was monitored by the 24-h ambulatory blood pressure monitoring, which is considered the gold standard in the diagnosis of hypertension [64]. In contrast, a recent meta-analysis [65] 
did not support walnut consumption per se as a blood pressure-lowering strategy. Despite being a meta-analysis, that study [65] may have had a few limitations due to heterogeneity. The results of Domènech et al. [63] provide what appears to be reliable evidence, based mainly on its long-term duration and sample size.

Le et al. [66] recruited 213 overweight and obese women to a weight loss study, and offered one of the three following dietary regimens: a walnut-rich diet which consisted of 35\% energy from fat and $45 \%$ energy from carbohydrates, or a low-fat (20\%) high-carbohydrate $(65 \%)$ diet, or a high-fat (35\%) low-carbohydrate (45\%) diet. After six months of intervention, high-density lipoprotein cholesterol (HDL-C) levels were significantly increased $(p<0.05)$ in the walnut-rich group (from $\approx 60$ to $\approx 63 \mathrm{mg} / \mathrm{dL}$ ), whilst a small decrease was observed in the low-fat (from $\approx 60$ to $\approx 57 \mathrm{mg} / \mathrm{dL}$ ) and low-carbohydrate (from $\approx 58$ to $\approx 57 \mathrm{mg} / \mathrm{dL}$ ) groups.

Interestingly, Fatahi et al. [67] randomised 99 overweight and obese women into three low energy-diet groups: the first group consisted of $300 \mathrm{~g} /$ week of fatty fish such as salmon, avoiding the intake of plant sources of n3-PUFAs; the second group consisted of 18 walnuts/week, avoiding the intake of fish and other plant sources of n3-PUFAs; the third group consisted of $150 \mathrm{~g}$ fatty fish and nine walnuts/week, avoiding the intake of other sources of n3-PUFAs. After 12 weeks of dietary intervention, as compared to the fish-only group and walnut-only group, the fish + walnut group showed better metabolic profile overall, evidenced by greater increase in HDL-C (+3.6 mg/dL) levels, followed with greater decrease in systolic blood pressure $(-5 \mathrm{mmHg})$, fasting blood glucose $(-12 \mathrm{mg} / \mathrm{dL})$, low-density lipoprotein cholesterol (LDL-C) $(-6 \mathrm{mg} / \mathrm{dL})$, high-sensitivity C-reactive protein (hs-CRP) $(-0.51 \mathrm{mg} / \mathrm{L})$, D-dimer $(-0.45 \mathrm{mg} / \mathrm{dL})$, fibrinogen $(-22 \mathrm{mg} / \mathrm{dL})$, alanine aminotransferase (ALT) (-6 IU/L), aspartate aminotransferase (AST) (-6 IU/L), TNF- $\alpha(-0.08 \mathrm{ng} / \mathrm{mL})$ and IL-6 $(-1.6 \mathrm{ng} / \mathrm{mL})$.

\subsubsection{Flaxseed}

Flaxseed is an important source of ALA, and a few trials have identified beneficial effects of flaxseed intake upon lipid indexes and cardiometabolic biomarkers. In a study recruiting 21 patients with coronary artery disease [68], a pivotal population to ascertain the magnitude of a cardiometabolic intervention, the daily consumption of $30 \mathrm{~g}$ flaxseed for 12 weeks promoted better outcomes as compared to the control group in increasing flow-mediated dilation (5.1 vs. $-0.55 \%$ change from baseline for the flaxseed and control groups, respectively), whilst decreasing the inflammatory status by reducing the levels of CRP $(-1.18 \mathrm{mg} / \mathrm{L})$, IL-6 $(-7.65 \mathrm{pg} / \mathrm{mL})$, and TNF- $\alpha(-34.73 \mathrm{pg} / \mathrm{mL})$. Importantly, no significant change in body weight was observed in either groups [68], which appears to be a very relevant result as it suggests that flaxseed may improve cardiovascular parameters independently of weight loss.

In a systematic review and meta-analysis of RCTs with 1502 patients across 32 studies, flaxseed or its derivatives (whole or ground flaxseed, flaxseed oil, or lignan supplements) reduced the concentrations of hs-CRP (weighted mean difference (WMD): $-0.75 ; 95 \%$ CI -1.19, -0.31) and TNF- $\alpha$ (WMD: -0.38 ; $95 \%$ CI $-0.75,-0.01$ ) but did not change IL-6 levels. Flaxseed was tested in the form of whole flaxseed, golden flaxseed, flaxseed oil, and lignan supplements at dosages ranging from $360 \mathrm{mg}$ to $60 \mathrm{~g}$, for 2 to 12 weeks, with an averaged intervention period of approximately 10 weeks [69].

A recently published clinical trial recruited 41 women suffering with polycystic ovary syndrome, randomly segregated into two groups, group 1 subjected to lifestyle changes (American Heart Association recommendations $+>30 \mathrm{~min}$ moderate to intense activity 3x/week) plus $30 \mathrm{~g} /$ day brown flaxseed flour in salad, yogurt or cold drinks, and group 2 subjected to the same lifestyle changes only, for 12 weeks [70]. The authors found that the flaxseed group showed significant improvements in insulin, homeostasis model assessment of insulin resistance (HOMA-IR), TG, hs-CRP, IL-6, leptin, HDL-C and adiponectin, as compared to the non-flaxseed group [70].

In a RCT recruiting 100 eligible patients suffering with non-alcoholic fatty liver disease (NAFLD), Yari et al. [71] found that $30 \mathrm{~g}$ flaxseed daily plus positive lifestyle interventions for 12 weeks decreased serum concentrations of total cholesterol (TC) (-31.71 mg/dL), TG (-61.33 mg/dL), 
LDL-C (-22.64 mg/dL), ALT (-11.12 U/L), AST (-5.37 U/L) and gamma-glutamyltransferase $(-11.54 \mathrm{U} / \mathrm{L})$, results that were not matched in the group submitted to positive lifestyle interventions only. It should be noted however that both groups showed reductions in BMI (30.37 \pm 4.42 to $28.05 \pm 3.89 \mathrm{~kg} / \mathrm{m}^{2}$ in the flaxseed plus lifestyle improvement group, and $33.37 \pm 5.56$ to $32.42 \pm 5.98$ in the lifestyle improvement only group) as well as the intensity of hepatic steatosis, a result most likely attributed to decreased energy intake in both groups (2379.41 \pm 473.74 to $2117.47 \pm 378.46$, and $2424.45 \pm 470.89$ to $1966.39 \pm 449.52 \mathrm{kcal}$, respectively). Such findings reinforce the hypothesis of beneficial effects of flaxseed independently of changes in energy intake and body composition.

In a mirrored RCT [72], this time recruiting 98 patients suffering with metabolic syndrome, the same researchers from the previously mentioned study [71] observed comparable results, in which $30 \mathrm{~g}$ flaxseed plus positive lifestyle interventions for 12 weeks reduced by $76 \%$ the prevalence of metabolic syndrome, whilst the lifestyle intervention only group had this parameter reduced by $36.4 \%$ ( $p=0.013$ for the difference between groups). Likewise, both groups reduced their calorie intake before versus after, but without differences between them (2423.04 \pm 468.98 to $2198.76 \pm 455.47$ and $2410.26 \pm 451.87$ to $2079.89 \pm 465.46$ for flaxseed and control groups, respectively).

\subsection{Oils}

\subsubsection{Lipid Profile of Oils}

Oils rich in ALA are a powerful tool to investigate the effects of ALA within a less complex matrix. Despite the presence of other fatty acids and fat-soluble compounds in the oil, the removal of fibre, vitamins, especially water-soluble ones, and water-soluble matter surely minimize the effects of confounding variables. Flaxseed, walnut, and rapeseed oils are, respectively, the main sources of ALA. Soybean oil is often considered a small to reasonable source of ALA, once research into its fatty acid composition has shown ALA concentrations ranging from 2.7\% to 7.8\% [73,74]. The n6-PUFAs content is nonetheless crucial when contemplating the $\mathrm{n} 3$ content of plant oils, as sunflower, corn, walnut, cottonseed, soybean, and peanut oils are important sources of n6-PUFAs (Table 2).

Table 2. ALA content and principal nutrition facts of selected edible oils.

\begin{tabular}{|c|c|c|c|c|c|c|c|c|c|}
\hline $\begin{array}{c}\text { Oil Type, } \\
1 \text { Tablespoon/13.6 g } \\
\text { [FDC ID] }\end{array}$ & $\begin{array}{l}\text { Energy } \\
\text { (kcal) }\end{array}$ & $\begin{array}{c}\text { Total } \\
\text { Lipid } \\
\text { (g) }\end{array}$ & $\begin{array}{l}\text { Vitamin } \\
\text { E (mg) }\end{array}$ & $\begin{array}{l}\text { Saturated } \\
\text { Fats }(\mathrm{g})\end{array}$ & $\begin{array}{l}\text { Monounsaturated } \\
\text { Fats (g) }\end{array}$ & $\begin{array}{l}\text { Polyunsaturated } \\
\text { Fats (g) }\end{array}$ & $\begin{array}{c}\text { LA, } \\
18: 2 / n-6 \\
\text { (g) }\end{array}$ & $\begin{array}{c}\text { ALA, } \\
18: 3 n-3 \\
\text { (g) }\end{array}$ & $\begin{array}{c}n-6 / n-3 \\
\text { Ratio }\end{array}$ \\
\hline Flaxseed oil [789037] & 120 & 13.6 & 0.064 & 1.22 & 2.51 & 9.23 & 1.95 & 7.26 & 0.26 \\
\hline Walnut oil [789048] & 120 & 13.6 & 0.054 & 1.24 & 3.1 & 8.61 & 7.19 & 1.41 & 5.09 \\
\hline Rapeseed oil [172336] & 120 & 13.6 & 2.38 & 1.01 & 8.64 & 3.82 & 2.58 & 1.24 & 2.08 \\
\hline Soybean oil [789045] & 120 & 13.6 & 1.11 & 2.13 & 3.1 & 7.85 & 6.93 & 0.92 & 7.53 \\
\hline Olive oil [789038] & 120 & 13.6 & 1.94 & 1.86 & 9.85 & 1.42 & 1.32 & 0.103 & 12.81 \\
\hline $\begin{array}{c}\text { Cottonseed oil } \\
\text { [789036] }\end{array}$ & 120 & 13.6 & 4.8 & 3.52 & 2.42 & 7.06 & 7 & 0.027 & 259.25 \\
\hline Coconut oil [789034] & 121 & 13.5 & 0.015 & 11.2 & 0.861 & 0.231 & 0.229 & 0.003 & 76.33 \\
\hline Peanut oil [789039] & 120 & 13.6 & 2.12 & 2.28 & 6.24 & 4.32 & 4.32 & 0 & - \\
\hline
\end{tabular}

Highest to lowest sources of ALA among common oils used for cooking. In addition, the main sources of LA can be noted, which are sunflower, corn, walnut, cottonseed, soybean, and peanut oils, respectively. Adapted from the United States Department of Agriculture (USDA) database [59].

\subsubsection{Flaxseed Oil}

A RCT investigated the effects of either $25 \mathrm{~mL} / \mathrm{d}$ flaxseed oil or $25 \mathrm{~mL} / \mathrm{d}$ sunflower oil administered for seven weeks to 60 patients suffering with metabolic syndrome [75]. Serum IL-6 levels decreased significantly in both groups ( 9.37 to $7.90 \mathrm{pg} / \mathrm{mL}, p<0.001$ for flaxseed oil, and 9.22 to $8.48 \mathrm{pg} / \mathrm{mL}$, $p<0.006$ for sunflower oil), but the flaxseed oil group presented a greater reduction $(p=0.017)$. 
Given that that was a dosage considered high, it is worth mentioning that no side effects were reported in either group [75]. Interestingly, in a study recruiting 60 women with gestational diabetes [76], the daily supplementation for 6 weeks with $2 \mathrm{~g} /$ day flaxseed oil capsules, which contained $800 \mathrm{mg} /$ day ALA, reduced the concentrations of TG $(-40.5 \mathrm{mg} / \mathrm{dL}), \mathrm{TC}(-22.7 \mathrm{mg} / \mathrm{dL})$, insulin $(-2.2 \mu \mathrm{IU} / \mathrm{mL})$, and hs-CRP $(-1.3 \mathrm{mg} / \mathrm{L})$, as compared to a matched group that received sunflower oil capsules. The flaxseed oil-receiving group also showed upregulated LDL receptor, downregulated IL-1 and TNF- $\alpha$ gene expression, decreased malondialdehyde levels and increased total nitrite and total glutathione levels.

In a recent study [77] recruiting 59 overweight and obese adults with stage I hypertension without pharmacological treatment, $10 \mathrm{~g}$ of refined cold-pressed flaxseed oil (4.7 g ALA) for 12 weeks decreased fasting free fatty acid $(-58 \mu \mathrm{mol} / \mathrm{L})$ and TNF- $\alpha(-0.14 \mathrm{pg} / \mathrm{mL})$ plasma concentrations. In contrast, no changes were found in other metabolic risk markers (e.g., serum glucose and TG levels) nor vascular function markers (e.g., brachial artery flow-mediated vasodilation, carotid-to-femoral pulse wave velocity, and retinal microvascular calibres) before versus after testing, both on fasting and postprandially. We consider this result to be extremely relevant for our critical discussion, as the ALA intake in that study was about three to five times higher than the recommended daily intake and, even so, it failed to improve cardiovascular markers. Furthermore, the volunteers of that study not only had obesity or overweight and stage I hypertension, their average age was $60 \pm 8$ years, a finding that is positively associated with vascular ageing, which by definition poses a greater risk for hypertension and atherosclerotic disease than the more traditional risk factors, including lipid and glucose levels, smoking and sedentary lifestyle [78].

The Omega-3 Index (O3I) reflects the relative percentage amount of EPA and DHA in erythrocyte membranes, and is considered a surrogate biomarker for cardiovascular events [79]. Cao et al. investigated in individuals with low baseline n3-PUFA levels the effects of supplementation with fish oil or flaxseed oil upon O3I [80]. Cao found that supplementing $2.1 \mathrm{~g} /$ day FO (1296 mg EPA $+864 \mathrm{mg}$ DHA) for eight weeks increased the O3I from $4.3 \%$ to $7.8 \%(p<0.001)$, followed by a gradual decline to $5.7 \%$ and to $3.8 \%$ at 4 and 16 weeks after the end of the supplementation period, respectively. On the other hand, supplementation with flaxseed oil (3510 mg ALA + $900 \mathrm{mg}$ LA/d) for the same period, in turn, did not significantly change the O3I, but it did increase not only EPA but also n3-docosapentaenoic acid (DPA) [80], a fatty acid that sits in between EPA and DHA in the elongation desaturation pathway.

It can be argued that the study of Cao et al. [80] did not cover a period of supplementation that would allow maximum incorporation and saturation of supplemented PUFAs into erythrocyte membranes, therefore not raising the O3I to its maximum achievable level. A O3I higher than $8 \%$ has been proposed to be favourable against cardiovascular events, whilst $\leq 4 \%$ is interpreted as low [24,79,81]. Accordingly, the benefits of ALA as a mitigator of cardiometabolic events can be supported by its role as a substrate for EPA. The latter is a well-known element against pro-inflammatory pathways in the cardiovascular system.

\subsubsection{Soybean Oil}

Despite having an obviously different fatty acid profile as compared to FO, soybean oil, unarguably, is a source of some ALA, and a few studies have already demonstrated a mild but relatively positive potential for soybean oil. For example, in treated hepatitis C patients $(n=52), 6000 \mathrm{mg} / \mathrm{day}$ FO or a soybean oil control for 12 weeks significantly decreased serum insulin levels (17.1 to $10.9 \mu \mathrm{IU} / \mathrm{mL}$ $p=0.001,12.6$ to $10.6 \mu \mathrm{IU} / \mathrm{mL} p=0.011$ for FO and soybean oil groups, respectively) and HOMA values (3.8 to $2.4 p=0.002,3.1$ to $3.0 p=0.046$ for FO and soybean oil groups, respectively) when comparing baseline versus end-of-intervention. The FO group was clearly more efficient; however, differences between both groups ( $p=0.016$ for insulin levels and $p=0.015$ for HOMA-IR values) have been observed [82].

In a small controlled clinical trial recruiting 16 hypercholesterolaemic women in a 10 weeks intervention, participants received an amount of soybean oil that consisted of $20 \%$ of their energy 
intake in a weight-maintaining diet with $<300 \mathrm{mg} /$ day of cholesterol [83]. The control group consisted of the same participants in a weight-maintaining diet with $<300 \mathrm{mg} /$ day of cholesterol for eight weeks but no soybean oil. As compared to the eight-week control period, TC, HDL-C, LDL-C and small dense low-density lipoprotein-cholesterol (sdLDL-C) levels were reduced at the end of the 10 week-soybean oil intervention period [83]. Furthermore, the sdLDL oxidation lag time was reduced after soybean oil consumption. In addition to the unfavourable cardiovascular conditions of maintaining low HDL-C levels, the former is linked to the pathophysiology of atherosclerotic disease due to the damage potential of sdLDL-C subclasses, especially in their oxidised form, on arterial structures [6].

\subsubsection{Rapeseed Oil}

In a meta-analysis of 27 RCTs [84], consumption of rapeseed oil was associated with reductions of approximately $7.24 \mathrm{mg} / \mathrm{dL}$ in TC $(95 \% \mathrm{CI},-12.1$ to -2.7$)$ and of approximately $6.4 \mathrm{mg} / \mathrm{dL}$ in LDL-C $(95 \%$ CI -10.8 to -2$)$ serum levels, as compared to sunflower oil and saturated fat. No changes were observed in TG nor HDL-C. Overall, the daily dose of rapeseed oil ranged from 12 to $50 \mathrm{~g}$ for 21 to 180 days. Most trials in that meta-analysis addressed individuals with lipid disorders and patients with heart disease, type 2 diabetes mellitus, obesity, metabolic syndrome, or non-alcoholic fatty liver disease. Importantly, the trials were under isocaloric conditions and, thus, partially avoided the bias of weight loss and its relationship with amelioration of lipid indices [84]. A clinical trial study in well-controlled conditions, recruiting 10 healthy men aged $25.3 \pm 1$ years, found that $24 \mathrm{~h}$ lipid oxidation was more pronounced when the participants received rapeseed oil-enriched meals for the duration of the study, as compared to a matched meal enriched with palm oil, a source of saturated fat [85].

It is well known that replacing dietary saturated fats with monounsaturated fatty acids (MUFAs) and PUFAs can reduce overall mortality [86]. The United Kingdom Scientific Advisory Committee on Nutrition in 2019 concluded that the recommendation for the population average contribution of saturated fat to total calorie intake should remain at no more than $10 \%$ of total dietary intake, and that reducing intakes of saturated fats reduces the risk of cardiovascular and heart disease events [87].

The alleged cholesterol-lowering properties of rapeseed oil could be attributed not only to its ALA content, but also possibly combined with its MUFA composition. Approximately $56 \%$ of the total fatty acids in rapeseed oil are MUFAs, with oleic acid as the most abundant one, at $54.5 \%$ of the total fatty acids, approximately [88]. The abundance of oleic acid in rapeseed oil may support its beneficial properties, as it has been shown that oleic acid elicits improvement on lipids and lipoproteins, as well as reduced risk of cardiovascular disease in humans [89]. The ALA content in rapeseed oil, in turn, is estimated at approximately 6 to $10 \%$ of total fatty acids [59,90,91]. Interestingly however, a study found a much lower ALA content in rapeseed oil, $\approx 1.2 \%$ [92].

A critical interpretation of published studies will see that other plant sources of MUFAs and PUFAs may show positive results in comparison to rapeseed oil. For instance, the consumption of sesame oil was more favourable for glycaemic control markers when compared to rapeseed oil in a recent RCT recruiting individuals with type 2 diabetes mellitus [91]. In that study, rapeseed oil increased serum fasting blood glucose $(+7.72 \pm 3.15 \mathrm{mg} / \mathrm{dL}, p<0.05)$, whilst sesame oil decreased serum insulin $(-6.00 \pm 1.72 \mathrm{mIU} / \mathrm{mL}, p<0.05)$ levels in a nine-week intervention period. The dietary recommendation was based on $30-32 \%$ of the total energy intake from fats but, despite the predominance of oil intake in each intervention, we noticed that the authors did not present in their study the exact or estimated amount of oil consumed. Some of the strengths of the study include its design, a triple-blind, cross-over clinical trial with 92 subjects completing all treatment periods, which were composed of four-week run-in and four-week wash-out periods based on sunflower oil. 


\subsection{Seaweed}

\subsubsection{Lipid Profile of Seaweed}

The use of seaweed for cooking and as a food supplement is gaining more popularity worldwide [93,94]. As a functional food, seaweed is a vegetarian source of n3-PUFAs, protein, and micronutrients [95]. Spirulina and chlorella are commercially available biomass extracts of cyanobacteria and green algae respectively, designed to attend a growing demand [96]. Both spirulina and chlorella are often claimed to be valuable sources of n3-PUFAs; however, the accuracy of such statement needs to be clarified in context, as to obtain approximately 2 to $3 \mathrm{~g}$ of total lipids from these microalgae it is necessary to ingest approximately $28 \mathrm{~g}$ of it in its powdered form. The total lipid content can be practically zero in supplemental dosages ( $\approx 3 \mathrm{~g} / \mathrm{day})$ [59].

Chlorella minutissima UTEX 2219 and UTEX 2341 feature $3.3 \%$ and 31.3\% EPA, respectively, of the total fatty acid content, but DHA was not detected in either strain [97]. In a fatty acid profile analysis of Spirulina platensis from seven commercially available products, EPA and DHA were detected in only two samples, contributing with $1.79 \%$ and $7.70 \%$, and $2.28 \%$ and $2.88 \%$, respectively, of the total fatty acids [98]. Similarly to flaxseed and nuts, whether the effects of dietary intervention with seaweed are attributed to its n3-PUFAs per se remain to be investigated, as the food matrix should be considered. Spirulina and Chlorella contain not only macro and micronutrients but also other compounds with antioxidant properties which may play a role in positive health outcomes [99-101].

\subsubsection{Clinical Findings}

A meta-analysis published in 2016 [102] found that in general the daily consumption of 1 to $10 \mathrm{~g}$ Spirulina led to significant improvements in lipid profile by reducing TC in $\approx 47 \mathrm{mg} / \mathrm{dL}$ (95\% CI: -67.31 to -26.22$)$, LDL-C in $\approx 41 \mathrm{mg} / \mathrm{dL}$ (95\% CI: -60.62 to -22.03$)$, TG in $\approx 44 \mathrm{mg} / \mathrm{dL}$ (95\% CI: -50.22 to -38.24 ), whilst increasing HDL-C in $\approx 6 \mathrm{mg} / \mathrm{dL}$ (95\% CI: 2.37-9.76). Seven placebo-controlled clinical trials with duration of 2-4 months were included in that meta-analysis, and the population appraised consisted of patients with diabetes, cardiac diseases, nephrotic syndrome and HIV infection, illnesses whose pathophysiologies are related to dyslipidaemia [103-105]. Seemingly, an effective and practical dose was about $4 \mathrm{~g}$ /day of Spirulina, which can be administered in capsules or powder [102]. Nevertheless, as discussed above, we believe that the n3-PUFAs content in Spirulina was not the sole player in yielding such outcomes.

Supplementation with $300 \mathrm{mg} /$ day of Chlorella for 8 weeks decreased TNF- $\alpha$ levels, in comparison with the placebo group, in a RCT of 70 patients with NAFLD [106]. An 8 week-long RCT investigating 44 women suffering with primary dysmenorrhea and supplemented with $1500 \mathrm{mg} / \mathrm{day}$ Chlorella found a significant reduction in hs-CRP levels (from $2590.00 \pm 1801.66$ to $974.21 \pm 292.85 \mathrm{ng} / \mathrm{mL}$ ), as compared to the control group [107].

In a Japanese sample population, 40 daily tablets of Chlorella were provided to 17 individuals with borderline high fasting blood glucose, TC, and TG levels, as well as to 17 healthy individuals [108]. After 16 weeks of supplementation, the researchers found reductions in body fat percentage, serum TC, and fasting blood glucose levels in both groups [108]. In our view however, that study appears to show a few limitations that should be considered in the context of a broader clinical scenario. The researchers did not measure food intake, there was no matched control group, and body fat percentage was obtained through bioelectrical impedance, which as a method of body composition analysis has some limitations [109]. Lastly, Chlorella supplementation was used in an impracticable dosage that, although it may be tested, cannot be translated into a broader clinical recommendation. As 40 tablets were ingested together with a considerable volume of fluid every day, probably this posology in itself with fluid may have resulted in lower food intake due to stomach filling. 


\section{Population}

Type 2 diabetes, obesity, dyslipidaemia and hypertension, conditions that we have attempted to address in the present study, are related to a pro-inflammatory state [110-113]. The evidence so far available suggests that the consumption of ALA-rich foodstuffs may attenuate the levels of inflammation-associated biomarkers. More importantly however, the consumption of ALA food sources appears to be associated with reduced incidence of cardiovascular events. Further long-term RCTs are imperative to further elucidate such preliminary findings.

In the context of liver diseases, NAFLD particularly, lifestyle improvement is a cornerstone in ameliorating the disease. We have identified studies that showed beneficial effects of ALA interventions in patients with NAFLD $[71,84]$. Accordingly, a favourable nutritional support based on ALA food sources could be considered in therapies for NAFLD patients in cases of low frequency of fatty fish intake or absence of FO supplementation.

Food sources of ALA may also be relevant during pregnancy and lactation due not only to their rich nutritional composition but also due to a thoroughly justified need to avoid complex herbal supplement mixtures that may jeopardize the health of the mother and of the child. Additionally, plant sources of n3-PUFAs could be seen as an option for pregnant women who do not tolerate fatty fish and for those who suffer with nausea and with hyperemesis gravidarum, relatively common manifestations during the gestational period [114,115]. The amount and profile of n3-PUFAs ingested by the lactating mother is paramount for infant health, as the mother's diet directly reflects upon her milk fatty acid profile [116].

Exclusively vegan diets are to be examined carefully due to the risk of n3-PUFAs deficiency. Apart from a lower intake of total and saturated fats, another characteristic of exclusively vegan diets is a higher proportional intake of n6-PUFAs, when compared to omnivorous and vegetarian diets $[110,117]$. For those reasons, recommendations for vegan diets that include appropriate amounts of ALA, necessarily combined with a balanced n3/n6 ratio, are paramount for the maintenance of long-term health.

It is widely accepted that peanut and peanut butter have been speculated by the layperson and by some health practitioners as friendly components of the exclusively vegan diet. Careful consideration however should be exercised regarding the amounts of peanut and peanut butter consumed, as a pilot study observed in 14 exercise-trained healthy individuals with an average age of 30 years that the daily consumption of approximately $103 \mathrm{~g}$ of peanut butter for 4 weeks led to changes in body composition, markedly increased body fat content [118]. Such results only confirm that careful calorie counting is pivotal when adding a new source of lipids to the diet plan, regardless of whether those are considered healthy food items. Furthermore, peanut is particularly rich in LA and virtually absent of ALA (Table 2).

\section{Decision-Making Practice}

A diet poor in n3-PUFAs and rich in n6-PUFAs in the long term leads to inflammation and increased risk of diseases, including cardiovascular diseases [119]. If the patient does not comply with a diet that includes fatty fish or FO supplements, ALA-rich foods are important to at least partially supply some of the $\mathrm{n} 3$ requirement, at the same time reducing the LA bioavailability. Furthermore, some individuals in society may choose not to adhere to food supplementation, be it because of added costs, dietary choices such as veganism and vegetarianism, the wish to avoid polypharmacy if they are already taking medicine tablets, or due to personal values. Such lifestyle choices and circumstances further emphasize the need for a careful nutritional planning that includes sources of n3-PUFAs.

Along those lines, some period supplementing FO and followed by some period incrementing plant sources of n3-PUFAs may be an example of what would be a "periodized" loading of n3 status. Such hypothesis can be sustained due to the incorporation of n3-PUFAs into cell membranes, which occurs over a few months after supplementation, whilst the period appears to be longer for decreasing n3 status than the progress of storage. In the case of the study of Cao et al. [80] for example, 
two months of FO supplementation was sufficient to almost achieve a reasonable n3 state, which was maintained by one month afterwards but returning to the same baseline level after 16 weeks of interruption. We believe that a "periodized" FO supplementation regimen could be conceivable two to three times a year for one to four months, followed with nutritional counselling and observing the intake of foodstuffs rich in ALA in the period without the FO supplementation, hoping to provide a better n3-DPA level. Nutritional advice however will always be tailored to the individual's needs and preferences, such as frequency of consumption of fatty fish and food sources of ALA, patient's income, and any coexisting morbidity. As nutritional strategy for individuals who, for one reason or another, do not eat fish nor take FO supplementation, adding in ALA-rich foods, e.g., flaxseed and chia seeds, or adding their oils within a dietary plan, alongside a careful consideration to dietary sources of n6-PUFAs, in itself seems to be paramount for long term overall health.

\section{Perspectives}

In the present study we focused on the effects of ALA found naturally in foodstuffs, seeds, nuts and oils, instead of isolated ALA supplementation. Further clinical research is urgently required to broaden the current knowledge of the potential of ALA upon cardiometabolic dysregulations and cardiometabolic protection. Well-designed RCTs could certainly minimize the residual confounding variables caused by other nutrients.

The limitations of our study, as well as of other studies that have investigated ALA cardiometabolic effects specifically, are many. Ultimately however, although the current study provides some insights in a real-world prescription-based intervention, we also encourage the execution of meta-analyses to expand the current knowledge of specific nutrients in specific populations, in an attempt to find ideal dose-responses, as well as to continuously update guidelines in nutrition and cardiology.

\section{Conclusions}

In case of suspected insufficient $\mathrm{n} 3$ status, such as in individuals with low intake of fatty fish, those who do not take FO supplement, and in vegan individuals with very narrow dietary habits, alternative plant sources of n3-PUFAs may be candidates for partially attending the n3 metabolic demands. Although plant sources of n3-PUFAs are less impactful on EPA and DHA levels, evidence suggests that those are foodstuffs positively associated with favourable cardiometabolic outcomes, which could be triggered by other plant components, in synergy with ALA. Not only ALA in isolation, but its proposed effect in combination with other plant fatty acids and other plant components such as fibre, potassium, magnesium, and non-essential substances, e.g., polyphenols and sterols, may be the players in yielding benefits in cardiovascular metabolism.

Consumption of walnuts and flaxseed seems to be the main plant sources of n3-PUFAs with strong scientific basis for translation into clinical practice. Regarding oil intake, we believe that flaxseed oil is more advantageous than walnut oil, because the former's ALA content is five times greater than that of the latter, which in turn, can be considered the second principal source of ALA. Although several studies have alluded to rapeseed and soybean oils as ALA sources, their ALA amount is slight when compared to flaxseed oil, so that a usual oil serving must be considered in order not to exceed the daily energy requirement in an attempt to achieve an optimal level of ALA. Regarding seaweed, Spirulina and Chlorella have gained attention but there are no discernible studies corroborating a relevant amount of n3-PUFAs in usual doses of supplementation. Seemingly, the benefits of seaweed over cardiometabolic markers appear to be driven by their antioxidant content.

The introduction of ALA-rich foods is a cornerstone for individuals looking for n3 sources beyond fish and fish oil. It is nevertheless of greatest concern that the proposal to increase the consumption of ALA ought to be integrated with a controlled calorie intake and controlled n6-PUFAs intake, since both of them can be raised concomitantly, thus ensuing in untoward effects such as increased fat mass and cardiometabolic dysregulations. 
Supplementary Materials: The following are available online at http://www.mdpi.com/2072-6643/12/10/3159/s1, Table S1: Identification of RCTs that investigated the effects of nuts and seeds rich in ALA through the database search, Table S2: Identification of RCTs that investigated the effects of ALA-rich oils through the database search, Table S3: Identification of RCTs that investigated the effects of seaweed through the database search, Table S4: Identification of recent RCTs that investigated the effects of fish oil supplementation through the database search.

Author Contributions: Conceptualization, H.O.S.; methodology, H.O.S., J.C.P.; writing—original draft preparation, H.O.S.; funding acquisition, A.A.B.; supervision, A.A.B. All authors have read and agreed to the published version of the manuscript.

Funding: The authors are grateful to the University of Worcester for funding the publication fees.

Conflicts of Interest: The authors declare no conflict of interest.

\section{References}

1. Emerging Risk Factors Collaboration; Di Angelantonio, E.; Gao, P.; Pennells, L.; Kaptoge, S.; Caslake, M.; Thompson, A.; Butterworth, A.S.; Sarwar, N.; Wormser, D.; et al. Lipid-related markers and cardiovascular disease prediction. JAMA 2012, 307, 2499-2506. [PubMed]

2. Rapsomaniki, E.; Timmis, A.; George, J.; Pujades-Rodriguez, M.; Shah, A.D.; Denaxas, S.; White, I.R.; Caulfield, M.J.; E Deanfield, J.; Smeeth, L.; et al. Blood pressure and incidence of twelve cardiovascular diseases: Lifetime risks, healthy life-years lost, and age-specific associations in 1.25 million people. Lancet 2014, 383, 1899-1911. [CrossRef]

3. Santos, H.O.; Macedo, R.C.O. Cocoa-induced (Theobroma cacao) effects on cardiovascular system: HDL modulation pathways. Clin. Nutr. ESPEN 2018, 27, 10-15. [CrossRef] [PubMed]

4. Santos, H.O.; da Silva, G.A.R. To what extent does cinnamon administration improve the glycemic and lipid profiles? Clin. Nutr. ESPEN 2018, 27, 1-9. [CrossRef]

5. Santos, H.O.; Bueno, A.A.; Mota, J.F. The effect of artichoke on lipid profile: A review of possible mechanisms of action. Pharmacol. Res. 2018, 137, 170-178. [CrossRef] [PubMed]

6. Santos, H.O.; Earnest, C.P.; Tinsley, G.M.; Izidoro, L.F.M.; Macedo, R.C.O. Small dense low-density lipoprotein-cholesterol (sdLDL-C): Analysis, effects on cardiovascular endpoints and dietary strategies. Prog. Cardiovasc. Dis. 2020, 63, 503-509. [CrossRef]

7. Santos, H.O.; Kones, R.; Rumana, U.; Earnest, C.P.; Izidoro, L.F.M.; Macedo, R.C.O. Lipoprotein(a): Current Evidence for a Physiologic Role and the Effects of Nutraceutical Strategies. Clin. Ther. 2019, 41, 1780-1797. [CrossRef]

8. Wang, P.; Zhang, Q.; Hou, H.; Liu, Z.; Wang, L.; Rasekhmagham, R.; Kord-Varkaneh, H.; Santos, H.O.; Yao, G. The effects of pomegranate supplementation on biomarkers of inflammation and endothelial dysfunction: A meta-analysis and systematic review. Complement. Ther. Med. 2020, 49, 102358. [CrossRef]

9. Santos, H.O.; Genario, R.; Gomes, G.K.; Schoenfeld, B.J. Cherry intake as a dietary strategy in sport and diseases: A review of clinical applicability and mechanisms of action. Crit. Rev. Food Sci. Nutr. 2020, 1-14. [CrossRef]

10. E Ramsden, C.; Zamora, D.; Majchrzak-Hong, S.; Faurot, K.R.; Broste, S.K.; Frantz, R.P.; Davis, J.M.; Ringel, A.; Suchindran, C.M.; Hibbeln, J.R. Re-evaluation of the traditional diet-heart hypothesis: Analysis of recovered data from Minnesota Coronary Experiment (1968-73). BMJ 2016, 353, i1246. [CrossRef]

11. Marklund, M.; Wu, J.H.; Imamura, F.; Del Gobbo, L.C.; Fretts, A.; De Goede, J.; Shi, P.; Tintle, N.; Wennberg, M.; Aslibekyan, S.; et al. Biomarkers of Dietary Omega-6 Fatty Acids and Incident Cardiovascular Disease and Mortality. Circulation 2019, 139, 2422-2436. [CrossRef] [PubMed]

12. Wu, J.H.Y.; Marklund, M.; Imamura, F.; Tintle, N.; Korat, A.V.A.; De Goede, J.; Zhou, X.; Yang, W.-S.; Otto, M.C.D.O.; Kröger, J.; et al. Omega- 6 fatty acid biomarkers and incident type 2 diabetes: Pooled analysis of individual-level data for 39740 adults from 20 prospective cohort studies. Lancet Diabetes Endocrinol. 2017, 5, 965-974. [CrossRef]

13. Skulas-Ray, A.C.; Wilson, P.W.; Harris, W.S.; Brinton, E.A.; Kris-Etherton, P.M.; Richter, C.K.; Jacobson, T.A.; Engler, M.B.; Miller, M.; Robinson, J.G.; et al. Omega-3 Fatty Acids for the Management of Hypertriglyceridemia: A Science Advisory From the American Heart Association. Circulation 2019, 140, e673-e691. [CrossRef] [PubMed]

14. Kris-Etherton, P.M.; Harris, W.S.; Appel, L.J. Fish consumption, fish oil, omega-3 fatty acids, and cardiovascular disease. Circulation 2002, 106, 2747-2757. [CrossRef] [PubMed] 
15. Weylandt, K.H.; Serini, S.; Chen, Y.Q.; Su, H.M.; Lim, K.; Cittadini, A.; Calviello, G. Omega-3 Polyunsaturated Fatty Acids: The Way Forward in Times of Mixed Evidence. BioMed Res. Int. 2015, 2015, 143109. [CrossRef] [PubMed]

16. Sagara, M.; Njelekela, M.; Teramoto, T.; Taguchi, T.; Mori, M.; Armitage, L.; Birt, N.; Birt, C.; Yamori, Y. Effects of docosahexaenoic Acid supplementation on blood pressure, heart rate, and serum lipids in Scottish men with hypertension and hypercholesterolemia. Int. J. Hypertens. 2011, 2011, 809198. [CrossRef]

17. Manger, M.S.; Strand, E.; Ebbing, M.; Seifert, R.; Refsum, H.; Nordrehaug, J.E.; Nilsen, D.W.; A Drevon, C.; Tell, G.S.; Øyvind, B.; et al. Dietary intake of $\mathrm{n}-3$ long-chain polyunsaturated fatty acids and coronary events in Norwegian patients with coronary artery disease. Am. J. Clin. Nutr. 2010, 92, 244-251. [CrossRef]

18. Abdelhamid, A.S.; Brown, T.J.; Brainard, J.S.; Biswas, P.; Thorpe, G.C.; Moore, H.J.; Deane, K.H.; Summerbell, C.D.; Worthington, H.V.; Song, F.; et al. Omega-3 fatty acids for the primary and secondary prevention of cardiovascular disease. Cochrane Database Syst. Rev. 2018, 7, CD003177.

19. Hilborn, R.; Amoroso, R.O.; Anderson, C.M.; Baum, J.K.; Branch, T.A.; Costello, C.; De Moor, C.L.; Faraj, A.; Hively, D.; Jensen, O.P.; et al. Effective fisheries management instrumental in improving fish stock status. Proc. Natl. Acad. Sci. USA 2020, 117, 2218-2224. [CrossRef]

20. Jackson, J.B. The future of the oceans past. Philos. Trans. R. Soc. B Biol. Sci. 2010, 365, 3765-3778. [CrossRef]

21. Moher, D.; Liberati, A.; Tetzlaff, J.; Altman, D.G.; Prisma Group. Preferred reporting items for systematic reviews and meta-analyses: The PRISMA statement. PLoS Med. 2009, 6, e1000097. [CrossRef]

22. Anderson, B.M.; Ma, D.W. Are all n-3 polyunsaturated fatty acids created equal? Lipids Health Dis. 2009 , 8, 33. [CrossRef] [PubMed]

23. Rapoport, S.I.; Rao, J.S.; Igarashi, M. Brain metabolism of nutritionally essential polyunsaturated fatty acids depends on both the diet and the liver. Prostaglandins Leukot. Essent. Fat. Acids 2007, 77, 251-261. [CrossRef] [PubMed]

24. Stark, K.D.; Van Elswyk, M.E.; Higgins, M.R.; Weatherford, C.A.; Salem, N., Jr. Global survey of the omega-3 fatty acids, docosahexaenoic acid and eicosapentaenoic acid in the blood stream of healthy adults. Prog. Lipid Res. 2016, 63, 132-152. [CrossRef] [PubMed]

25. Burdge, G.C. Metabolism of alpha-linolenic acid in humans. Prostaglandins Leukot. Essent. Fat. Acids. 2006, 75, 161-168. [CrossRef] [PubMed]

26. Pawlosky, R.J.; Hibbeln, J.R.; Novotny, J.A.; Salem, N., Jr. Physiological compartmental analysis of alpha-linolenic acid metabolism in adult humans. J. Lipid Res. 2001, 42, 1257-1265.

27. Plourde, M.; Cunnane, S.C. Extremely limited synthesis of long chain polyunsaturates in adults: Implications for their dietary essentiality and use as supplements. Appl. Physiol. Nutr. Metab. 2007, 32, 619-634. [CrossRef]

28. Lin, Y.H.; Llanos, A.; Mena, P.; Uauy, R.; Salem, N.; Jr Pawlosky, R.J. Compartmental analyses of 2H5-alpha-linolenic acid and C-U-eicosapentaenoic acid toward synthesis of plasma labeled 1, 6n-3 in newborn term infants. Am. J. Clin. Nutr. 2010, 92, 284-293. [CrossRef]

29. Lin, Y.H.; Salem, N., Jr. Whole body distribution of deuterated linoleic and alpha-linolenic acids and their metabolites in the rat. J. Lipid Res. 2007, 48, 2709-2724. [CrossRef]

30. Wada, M.; Delong, C.J.; Hong, Y.H.; Rieke, C.J.; Song, I.; Sidhu, R.S.; Yuan, C.; Warnock, M.; Schmaier, A.H.; Yokoyama, C.; et al. Enzymes and receptors of prostaglandin pathways with arachidonic acid-derived versus eicosapentaenoic acid-derived substrates and products. J. Biol. Chem. 2007, 282, 22254-22266. [CrossRef]

31. Kromhout, D.; Yasuda, S.; Geleijnse, J.M.; Shimokawa, H. Fish oil and omega-3 fatty acids in cardiovascular disease: Do they really work? Eur. Heart J. 2012, 33, 436-443. [CrossRef] [PubMed]

32. Back, M. Omega-3 fatty acids in atherosclerosis and coronary artery disease. Future Sci. OA 2017, 3, FSO236. [CrossRef] [PubMed]

33. Fischer, R.; Konkel, A.; Mehling, H.; Blossey, K.; Gapelyuk, A.; Wessel, N.; Von Schacky, C.; Dechend, R.; Muller, D.N.; Rothe, M.; et al. Dietary omega-3 fatty acids modulate the eicosanoid profile in man primarily via the CYP-epoxygenase pathway. J. Lipid Res. 2014, 55, 1150-1164. [CrossRef] [PubMed]

34. Balogun, K.A.; Cheema, S.K. Cardioprotective Role of Omega-3 Polyunsaturated Fatty Acids Through the Regulation of Lipid Metabolism. In Pathophysiology and Pharmacotherapy of Cardiovascular Disease; Adis: Cham, Switzerland, 2015; pp. 563-588. 
35. Micha, R.; Khatibzadeh, S.; Shi, P.; Fahimi, S.; Lim, S.; Andrews, K.G.; Engell, R.E.; Powles, J.; Ezzati, M.; Mozaffarian, D.; et al. Global, regional, and national consumption levels of dietary fats and oils in 1990 and 2010: A systematic analysis including 266 country-specific nutrition surveys. BMJ 2014, 348, g2272. [CrossRef] [PubMed]

36. Blasbalg, T.L.; Hibbeln, J.R.; Ramsden, C.E.; Majchrzak, S.F.; Rawlings, R.R. Changes in consumption of omega-3 and omega-6 fatty acids in the United States during the 20th century. Am. J. Clin. Nutr. 2011, 93, 950-962. [CrossRef] [PubMed]

37. Hibbeln, J.R.; Nieminen, L.R.; Blasbalg, T.L.; Riggs, J.A.; Lands, W.E. Healthy intakes of n-3 and n-6 fatty acids: Estimations considering worldwide diversity. Am. J. Clin. Nutr. 2006, 83, 1483S-1493S. [CrossRef]

38. Cranmer-Byng, M.M.; Liddle, D.M.; De Boer, A.A.; Monk, J.M.; Robinson, L.E. Proinflammatory effects of arachidonic acid in a lipopolysaccharide-induced inflammatory microenvironment in 3T3-L1 adipocytes in vitro. Appl. Physiol. Nutr. Metab. 2015, 40, 142-154. [CrossRef]

39. Zivkovic, A.M.; Telis, N.; German, J.B.; Hammock, B.D. Dietary omega-3 fatty acids aid in the modulation of inflammation and metabolic health. Calif. Agric. 2011, 65, 106-111. [CrossRef]

40. Francis, A.A.; Deniset, J.F.; Austria, J.A.; Lavalleé, R.K.; Maddaford, G.G.; Hedley, T.E.; Dibrov, E.; Pierce, G.N. Effects of dietary flaxseed on atherosclerotic plaque regression. Am. J. Physiol. Circ. Physiol. 2013, 304, H1743-H1751. [CrossRef]

41. Dupasquier, C.M.C.; Dibrov, E.; Kneesh, A.L.; Cheung, P.K.M.; Lee, K.G.Y.; Alexander, H.K.; Yeganeh, B.K.; Moghadasian, M.H.; Pierce, G.N. Dietary flaxseed inhibits atherosclerosis in the LDL receptor-deficient mouse in part through antiproliferative and anti-inflammatory actions. Am. J. Physiol. Circ. Physiol. 2007, 293, H2394-H2402. [CrossRef]

42. Li, G.; Wang, X.; Yang, H.; Zhang, P.; Wu, F.; Li, Y.; Zhou, Y.; Zhang, X.; Ma, H.; Zhang, W.; et al. alpha-Linolenic acid but not linolenic acid protects against hypertension: Critical role of SIRT3 and autophagic flux. Cell Death Dis. 2020, 11, 83. [CrossRef] [PubMed]

43. Ren, J.; Chung, S.H. Anti-inflammatory effect of alpha-linolenic acid and its mode of action through the inhibition of nitric oxide production and inducible nitric oxide synthase gene expression via NF-kappaB and mitogen-activated protein kinase pathways. J. Agric. Food Chem. 2007, 55, 5073-5080. [CrossRef] [PubMed]

44. Calvo, M.J.; Martínez, M.S.; Torres, W.; Chávez-Castillo, M.; Luzardo, E.; Villasmil, N.; Salazar, J.; Velasco, M.; Bermúdez, V. Omega-3 polyunsaturated fatty acids and cardiovascular health: A molecular view into structure and function. Vessel Plus 2017, 1, 116-128. [CrossRef]

45. Backes, J.; Anzalone, D.; Hilleman, D.; Catini, J. The clinical relevance of omega-3 fatty acids in the management of hypertriglyceridemia. Lipids Health Dis. 2016, 15, 118. [CrossRef]

46. Zuniga, J.; Cancino, M.; Medina, F.; Varela, P.; Vargas, R.; Tapia, G.; Videla, L.A.; Fernández, V. N-3 PUFA supplementation triggers PPAR-alpha activation and PPAR-alpha/NF-kappaB interaction: Anti-inflammatory implications in liver ischemia-reperfusion injury. PLoS ONE 2011, 6, e28502. [CrossRef]

47. Hardwick, J.P.; Osei-Hyiaman, D.; Wiland, H.; Abdelmegeed, M.A.; Song, B.J. PPAR/RXR Regulation of Fatty Acid Metabolism and Fatty Acid omega-Hydroxylase (CYP4) Isozymes: Implications for Prevention of Lipotoxicity in Fatty Liver Disease. PPAR Res. 2009, 2009, 952734. [CrossRef]

48. Jump, D.B.; Lytle, K.A.; Depner, C.M.; Tripathy, S. Omega-3 polyunsaturated fatty acids as a treatment strategy for nonalcoholic fatty liver disease. Pharmacol. Ther. 2018, 181, 108-125. [CrossRef]

49. Reynolds, A.; Mann, J.; Cummings, J.; Winter, N.; Mete, E.; Te Morenga, L. Carbohydrate quality and human health: A series of systematic reviews and meta-analyses. Lancet 2019, 393, 434-445. [CrossRef]

50. Del Bo, C.; Bernardi, S.; Marino, M.; Porrini, M.; Tucci, M.; Guglielmetti, S.; Cherubini, A.; Carrieri, B.; Kirkup, B.M.; Kroon, P.A.; et al. Systematic Review on Polyphenol Intake and Health Outcomes: Is there Sufficient Evidence to Define a Health-Promoting Polyphenol-Rich Dietary Pattern? Nutrients 2019, 11, 1355.

51. Ros, E.; Hu, F.B. Consumption of plant seeds and cardiovascular health: Epidemiological and clinical trial evidence. Circulation 2013, 128, 553-565. [CrossRef]

52. Anderson, J.J.; Kruszka, B.; Delaney, J.A.; He, K.; Burke, G.L.; Alonso, A.; Bild, D.E.; Budoff, M.; Michos, E.D. Calcium Intake From Diet and Supplements and the Risk of Coronary Artery Calcification and its Progression Among Older Adults: 10-Year Follow-up of the Multi-Ethnic Study of Atherosclerosis (MESA). J. Am. Hear. Assoc. 2016, 5, e003815. [CrossRef] [PubMed] 
53. Budoff, M.J.; Young, R.; Burke, G.L.; Carr, J.J.; Detrano, R.; Folsom, A.R.; Kronmal, R.; Lima, J.A.C.; Liu, K.; McClelland, R.L.; et al. Ten-year association of coronary artery calcium with atherosclerotic cardiovascular disease (ASCVD) events: The multi-ethnic study of atherosclerosis (MESA). Eur. Heart J. 2018, 39, 2401-2408. [CrossRef] [PubMed]

54. Kanbay, M.; Bayram, Y.; Solak, Y.; Sanders, P.W. Dietary potassium: A key mediator of the cardiovascular response to dietary sodium chloride. J. Am. Soc. Hypertens. 2013, 7, 395-400. [CrossRef] [PubMed]

55. Reid, I.R.; Birstow, S.M.; Bolland, M.J. Calcium and Cardiovascular Disease. Endocrinol. Metab. 2017, 32, $339-349$. [CrossRef]

56. Rosique-Esteban, N.; Guasch-Ferre, M.; Hernandez-Alonso, P.; Salas-Salvado, J. Dietary Magnesium and Cardiovascular Disease: A Review with Emphasis in Epidemiological Studies. Nutrients 2018, 10, 168. [CrossRef]

57. Zhubi-Bakija, F.; Bajraktari, G.; Bytyçi, I.; Mikhailidis, D.P.; Henein, M.Y.; Latkovskis, G.; Rexhaj, Z.; Zhubi, E.; Banach, M.; Alnouri, F.; et al. The impact of type of dietary protein, animal versus vegetable, in modifying cardiometabolic risk factors: A position paper from the International Lipid Expert Panel (ILEP). Clin. Nutr. 2020. [CrossRef]

58. Shan, Z.; Guo, Y.; Hu, F.B.; Liu, L.; Qi, Q. Association of Low-Carbohydrate and Low-Fat Diets with Mortality Among US Adults. JAMA Intern. Med. 2020, 180, 513. [CrossRef]

59. United States Department of Agriculture. USDA National Nutrient Database for Standard Reference; USDA: Washington, DC, USA, 2015.

60. Institute of Medicine FaNB. Dietary Reference intakes for Energy, Carbohydrate, Fiber, Fat, Fatty Acids, Cholesterol, Protein, and Amino Acids (Macronutrients); National Academy Press: Washington, DC, USA, 2005.

61. Yang, L.; Guo, Z.; Qi, S.; Fang, T.; Zhu, H.; Santos, H.O.; Wong, C.H.; Qiu, Z. Walnut intake may increase circulating adiponectin and leptin levels but does not improve glycemic biomarkers: A systematic review and meta-analysis of randomized clinical trials. Complement. Ther. Med. 2020, 52, 102505. [CrossRef]

62. Fang, Z.; Dang, M.; Zhang, W.; Wang, Y.; Kord-Varkaneh, H.; Nazary-Vannani, A.; Santos, H.O.; Tan, S.C.; Clark, C.C.; Zanghelini, F.; et al. Effects of walnut intake on anthropometric characteristics: A systematic review and dose-response meta-analysis of randomized controlled trials. Complement. Ther. Med. 2020, 50, 102395. [CrossRef]

63. Domènech, M.; Serra-Mir, M.; Roth, I.; Freitas-Simoes, T.; Valls-Pedret, C.; Cofán, M.; López, A.; Sala-Vila, A.; Calvo, C.; Rajaram, S.; et al. Effect of a Walnut Diet on Office and 24-Hour Ambulatory Blood Pressure in Elderly Individuals. Hypertension 2019, 73, 1049-1057. [CrossRef]

64. Peixoto, A.J. Practical Aspects of Home and Ambulatory Blood Pressure Monitoring. Methodist DeBakey Cardiovasc. J. 2015, 11, 214-218. [CrossRef] [PubMed]

65. Li, J.; Jiang, B.; HOS Santos, D.; Singh, A.; Wang, L. Effects of walnut intake on blood pressure: A systematic review and meta-analysis of randomized controlled trials. Phytother. Res. 2020. [CrossRef] [PubMed]

66. Le, T.; Flatt, S.W.; Natarajan, L.; Pakiz, B.; Quintana, E.L.; Heath, D.D.; Rana, B.K.; Rock, C.L. Effects of Diet Composition and Insulin Resistance Status on Plasma Lipid Levels in a Weight Loss Intervention in Women. J. Am. Hear. Assoc. 2016, 5, e002771. [CrossRef]

67. Fatahi, S.; Haghighatdoost, F.; Larijani, B.; Azadbakht, L. Effect of Weight Reduction Diets Containing Fish, Walnut or Fish plus Walnut on Cardiovascular Risk Factors in Overweight and Obese Women. Arch. Iran. Med. 2019, 22, 574-583. [PubMed]

68. Khandouzi, N.; Zahedmehr, A.; Mohammadzadeh, A.; Sanati, H.R.; Nasrollahzadeh, J. Effect of flaxseed consumption on flow-mediated dilation and inflammatory biomarkers in patients with coronary artery disease: A randomized controlled trial. Eur. J. Clin. Nutr. 2019, 73, 258-265. [CrossRef] [PubMed]

69. Rahimlou, M.; Jahromi, N.B.; Hasanyani, N.; Ahmadi, A.R. Effects of Flaxseed Interventions on Circulating Inflammatory Biomarkers: A Systematic Review and Meta-Analysis of Randomized Controlled Trials. Adv. Nutr. 2019, 10, 1108-1119. [CrossRef] [PubMed]

70. Haidari, F.; Banaei-Jahromi, N.; Zakerkish, M.; Ahmadi, K. The effects of flaxseed supplementation on metabolic status in women with polycystic ovary syndrome: A randomized open-labeled controlled clinical trial. Nutr. J. 2020, 19, 8. [CrossRef]

71. Yari, Z.; Cheraghpour, M.; Alavian, S.M.; Hedayati, M.; Eini-Zinab, H.; Hekmatdoost, A. The efficacy of flaxseed and hesperidin on non-alcoholic fatty liver disease: An open-labeled randomized controlled trial. Eur. J. Clin. Nutr. 2020, 1-13. [CrossRef] 
72. Yari, Z.; Cheraghpour, M.; Hekmatdoost, A. Flaxseed and/or hesperidin supplementation in metabolic syndrome: An open-labeled randomized controlled trial. Eur. J. Nutr. 2020, 1-12. [CrossRef]

73. Alves, A.Q.; Da Silva, V.A.; Góes, A.J.S.; Silva, M.S.; De Oliveira, G.G.; Bastos, I.V.G.A.; Neto, A.G.D.C.; Alves, A.J. The Fatty Acid Composition of Vegetable Oils and Their Potential Use in Wound Care. Adv. Ski. Wound Care. 2019, 32, 1-8. [CrossRef]

74. Kim, J.; Kim, D.N.; Lee, S.H.; Yoo, S.H.; Lee, S. Correlation of fatty acid composition of vegetable oils with rheological behaviour and oil uptake. Food Chem. 2010, 118, 398-402. [CrossRef]

75. Akrami, A.; Makiabadi, E.; Askarpour, M.; Zamani, K.; Hadi, A.; Mokari-Yamchi, A.; Babajafari, S.; Faghih, S.; Hojhabrimanesh, A. A Comparative Study of the Effect of Flaxseed Oil and Sunflower Oil on the Coagulation Score, Selected Oxidative and Inflammatory Parameters in Metabolic Syndrome Patients. Clin. Nutr. Res. 2020, 9, 63-72. [CrossRef] [PubMed]

76. Jamilian, M.; Tabassi, Z.; Reiner, Ž.; Panahandeh, I.; Naderi, F.; Aghadavood, E.; Amirani, E.; Taghizadeh, M.; Shafabakhsh, R.; Satari, M.; et al. The effects of n-3 fatty acids from flaxseed oil on genetic and metabolic profiles in patients with gestational diabetes mellitus: A randomised, double-blind, placebo-controlled trial. Br. J. Nutr. 2020, 123, 792-799. [CrossRef] [PubMed]

77. Joris, P.J.; Draijer, R.; Fuchs, D.; Mensink, R.P. Effect of alpha-linolenic acid on vascular function and metabolic risk markers during the fasting and postprandial phase: A randomized placebo-controlled trial in untreated (pre-)hypertensive individuals. Clin. Nutr. 2020, 39, 2413-2419. [CrossRef]

78. Jani, B.; Rajkumar, C. Ageing and vascular ageing. Postgrad. Med. J. 2006, 82, 357-362. [CrossRef]

79. Harris, W.S.; Sands, S.A.; Windsor, S.L.; Ali, H.A.; Stevens, T.L.; Magalski, A.; Porter, C.B.; Borkon, A.M. Omega-3 fatty acids in cardiac biopsies from heart transplantation patients: Correlation with erythrocytes and response to supplementation. Circulation 2004, 110, 1645-1649. [CrossRef]

80. Cao, J.; Schwichtenberg, K.A.; Hanson, N.Q.; Tsai, M.Y. Incorporation and clearance of omega-3 fatty acids in erythrocyte membranes and plasma phospholipids. Clin. Chem. 2006, 52, 2265-2272. [CrossRef]

81. Hals, P.A.; Wang, X.; Piscitelli, F.; Di Marzo, V.; Xiao, Y.F. The time course of erythrocyte membrane fatty acid concentrations during and after treatment of non-human primates with increasing doses of an omega-3 rich phospholipid preparation derived from krill-oil. Lipids Health Dis. 2017, 16, 16. [CrossRef] [PubMed]

82. Freire, T.O.; Boulhosa, R.S.S.B.; Oliveira, L.P.M.; De Jesus, R.P.; Cavalcante, L.N.; Lemaire, D.C.; Toralles, M.B.P.; Lyra, L.G.C.; Lyra, A.C. n-3 polyunsaturated fatty acid supplementation reduces insulin resistance in hepatitis C virus infected patients: A randomised controlled trial. J. Hum. Nutr. Diet. 2016, 29, 345-353. [CrossRef] [PubMed]

83. Utarwuthipong, T.; Komindr, S.; Pakpeankitvatana, V.; Songchitsomboon, S.; Thongmuang, N. Small dense low-density lipoprotein concentration and oxidative susceptibility changes after consumption of soybean oil, rice bran oil, palm oil and mixed rice bran/palm oil in hypercholesterolaemic women. J. Int. Med. Res. 2009, 37, 96-104. [CrossRef] [PubMed]

84. Ghobadi, S.; Hassanzadeh-Rostami, Z.; Mohammadian, F.; Zare, M.; Faghih, S. Effects of Canola Oil Consumption on Lipid Profile: A Systematic Review and Meta-Analysis of Randomized Controlled Clinical Trials. J. Am. Coll. Nutr. 2019, 38, 185-196. [CrossRef]

85. Yajima, K.; Iwayama, K.; Ogata, H.; Park, I.; Tokuyama, K. Meal rich in rapeseed oil increases 24-h fat oxidation more than meal rich in palm oil. PLoS ONE 2018, 13, e0198858. [CrossRef] [PubMed]

86. Wang, D.D.; Li, Y.; Chiuve, S.E.; Stampfer, M.J.; Manson, J.E.; Rimm, E.B.; Willett, W.C.; Hu, F.B. Association of Specific Dietary Fats with Total and Cause-Specific Mortality. JAMA Intern. Med. 2016, 176, 1134-1145. [CrossRef] [PubMed]

87. The Scientific Advisory Committee on Nutrition. Saturated Fats and Health: SACN Report; SACN: Vissenbjerg, Denmark, 2019.

88. Vehovský, K.; Stupka, R.; Zadinová, K.; Šprysl, M.; Okrouhlá, M.; Lebedová, N.; Mlyneková, E.; Čítek, J. Effect of dietary rapeseed and soybean oil on growth performance, carcass traits, and fatty acid composition of pigs. Rev. Bras. Zootec. 2019, 48, 48. [CrossRef]

89. Bowen, K.J.; Kris-Etherton, P.; West, S.G.; A Fleming, J.; Connelly, P.W.; Lamarche, B.; Couture, P.; A Jenkins, D.J.; Taylor, C.G.; Zahradka, P.; et al. Diets Enriched with Conventional or High-Oleic Acid Canola Oils Lower Atherogenic Lipids and Lipoproteins Compared to a Diet with a Western Fatty Acid Profile in Adults with Central Adiposity. J. Nutr. 2019, 149, 471-478. [CrossRef] 
90. Zambiazi, R.C.; Przybylski, R.; Zambiazi , M.W.; Mendonça, C.B. Fatty acid composition of vegetable oils and fats. Bol. Cent. Pesqui. Process. Aliment. 2007, 25, 111-120.

91. Raeisi-Dehkordi, H.; Amiri, M.; Zimorovat, A.; Moghtaderi, F.; Zarei, S.; Forbes, S.C.; Salehi-Abargouei, A. The effects of canola oil compared with sesame and sesame-canola oil on glycemic control and liver function enzymes in patients with type 2 diabetes: A 3-way randomized triple-blind cross-over clinical trial. Diabetes/Metab. Res. Rev. 2020, e3399. [CrossRef]

92. Orsavova, J.; Misurcova, L.; Ambrozova, J.V.; Vicha, R.; Mlcek, J. Fatty Acids Composition of Vegetable Oils and Its Contribution to Dietary Energy Intake and Dependence of Cardiovascular Mortality on Dietary Intake of Fatty Acids. Int. J. Mol. Sci. 2015, 16, 12871-12890. [CrossRef]

93. Khan, M.I.; Shin, J.H.; Kim, J.D. The promising future of microalgae: Current status, challenges, and optimization of a sustainable and renewable industry for biofuels, feed, and other products. Microb. Cell Factories 2018, 17, 36. [CrossRef]

94. Kent, M.; Welladsen, H.M.; Mangott, A.; Li, Y. Nutritional evaluation of Australian microalgae as potential human health supplements. PLoS ONE 2015, 10, e0118985. [CrossRef]

95. Panahi, Y.; Darvishi, B.; Jowzi, N.; Beiraghdar, F.; Sahebkar, A. Chlorella vulgaris: A Multifunctional Dietary Supplement with Diverse Medicinal Properties. Curr. Pharm. Des. 2016, 22, 164-173. [CrossRef] [PubMed]

96. Andrade, L.M.; Andrade, C.J.; Dias, M.; Nascimento, C.A.O.; Mendes, M.A. Chlorella and spirulina microalgae as sources of functional foods, nutraceuticals, and food supplements; an overview. MOJ Food Process. Technol. 2018, 6, 45-58. [CrossRef]

97. Vazhappilly, R.; Chen, F. Eicosapentaenoic Acid and Docosahexaenoic Acid Production Potential of Microalgae and Their Heterotrophic Growth. J. Am. Oil Chem. Soc. 1998, 75, 393-397. [CrossRef]

98. Diraman, H.; Koru, E.; Dibeklioglu, H. Fatty Acid Profile of Spirulina platensis Used as a Food Supplement. Isr. J. Aquac. 2009, 61, 134-142.

99. Deng, R.; Chow, T.J. Hypolipidemic, antioxidant, and antiinflammatory activities of microalgae Spirulina. Cardiovasc. Ther. 2010, 28, e33-e45. [CrossRef]

100. Lee, S.H.; Kang, H.J.; Lee, H.J.; Kang, M.H.; Park, Y.K. Six-week supplementation with Chlorella has favorable impact on antioxidant status in Korean male smokers. Nutrition 2010, 26, 175-183. [CrossRef]

101. Dartsch, P.C. Antioxidant potential of selected Spirulina platensis preparations. Phytother. Res. 2008, 22, $627-633$. [CrossRef]

102. Serban, M.-C.; Sahebkar, A.; Dragan, S.; Stoichescu-Hogea, G.; Ursoniu, S.; Andrica, F.; Banach, M. A systematic review and meta-analysis of the impact of Spirulina supplementation on plasma lipid concentrations. Clin. Nutr. 2016, 35, 842-851. [CrossRef]

103. Goldberg, I.J. Clinical review 124: Diabetic dyslipidemia: Causes and consequences. J. Clin. Endocrinol. Metab. 2001, 86, 965-971. [CrossRef]

104. Lo, J. Dyslipidemia and lipid management in HIV-infected patients. Curr. Opin. Endocrinol. Diabetes Obes. 2011, 18, 144-147. [CrossRef]

105. Mikolasevic, I.; Zutelija, M.; Mavrinac, V.; Orlic, L. Dyslipidemia in patients with chronic kidney disease: Etiology and management. Int. J. Nephrol. Renov. Dis. 2017, 10, 35-45. [CrossRef] [PubMed]

106. Ebrahimi-Mameghani, M.; Sadeghi, Z.; Abbasalizad Farhangi, M.; Vaghef-Mehrabany, E.; Aliashrafi, S. Glucose homeostasis, insulin resistance and inflammatory biomarkers in patients with non-alcoholic fatty liver disease: Beneficial effects of supplementation with microalgae Chlorella vulgaris: A double-blind placebo-controlled randomized clinical trial. Clin. Nutr. 2017, 36, 1001-1006. [CrossRef] [PubMed]

107. Haidari, F.; Homayouni, F.; Helli, B.; Haghighizadeh, M.H.; Farahmandpour, F. Effect of chlorella supplementation on systematic symptoms and serum levels of prostaglandins, inflammatory and oxidative markers in women with primary dysmenorrhea. Eur. J. Obstet. Gynecol. Reprod. Biol. 2018, 229, 185-189. [CrossRef]

108. Mizoguchi, T.; Takehara, I.; Masuzawa, T.; Saito, T.; Naoki, Y. Nutrigenomic studies of effects of Chlorella on subjects with high-risk factors for lifestyle-related disease. J. Med. Food 2008, 11, 395-404. [CrossRef] [PubMed]

109. Khalil, S.F.; Mohktar, M.S.; Ibrahim, F. The theory and fundamentals of bioimpedance analysis in clinical status monitoring and diagnosis of diseases. Sensors 2014, 14, 10895-10928. [CrossRef]

110. Rogerson, D. Vegan diets: Practical advice for athletes and exercisers. J. Int. Soc. Sports Nutr. 2017, 14, 36. [CrossRef] 
111. Ellulu, M.S.; Patimah, I.; Khaza'ai, H.; Rahmat, A.; Abed, Y. Obesity and inflammation: The linking mechanism and the complications. Arch. Med. Sci. 2017, 13, 851-863. [CrossRef]

112. Esteve, E.; Ricart, W.; Fernandez-Real, J.M. Dyslipidemia and inflammation: An evolutionary conserved mechanism. Clin. Nutr. 2005, 24, 16-31. [CrossRef]

113. Nishi, M.; Seki, M. Degree of infiltration and prognosis of early cancer of the stomach; with special reference to early cancer with elevated lesion. Naika Intern. Med. 1970, 26, 102-116.

114. Chan, R.L.; Olshan, A.F.; Savitz, D.A.; Herring, A.H.; Daniels, J.L.; Peterson, H.B.; Martin, S.L. Maternal influences on nausea and vomiting in early pregnancy. Matern. Child Health J. 2011, 15, 122-127. [CrossRef]

115. McCarthy, F.P.; Lutomski, J.E.; Greene, R.A. Hyperemesis gravidarum: Current perspectives. Int. J. Women's Health 2014, 6, 719-725.

116. Barrera, C.; Valenzuela, A.; Chamorro, R.; Bascuñán, K.; Sandoval, J.; Sabag, N.; Valenzuela, F.; Valencia, M.-P.; Puigrredon, C.; Valenzuela, A. The Impact of Maternal Diet during Pregnancy and Lactation on the Fatty Acid Composition of Erythrocytes and Breast Milk of Chilean Women. Nutrients 2018, 10, 839. [CrossRef] [PubMed]

117. Clarys, P.; Deliens, T.; Huybrechts, I.; Deriemaeker, P.; Vanaelst, B.; De Keyzer, W.; Hebbelinck, M.; Mullie, P. Comparison of nutritional quality of the vegan, vegetarian, semi-vegetarian, pesco-vegetarian and omnivorous diet. Nutrients 2014, 6, 1318-1332. [CrossRef] [PubMed]

118. Antonio, J.; Axelrod, C.; Ellerbroek, A.; Carson, C.; Burgess, V.; Silver, T.; Peacock, C.A. The Effect of Peanut Butter Overfeeding in Trained Men and Women: A Pilot Trial. J. Exerc. Nutr. 2018, 1, 5-6.

119. Russo, G.L. Dietary n-6 and n-3 polyunsaturated fatty acids: From biochemistry to clinical implications in cardiovascular prevention. Biochem. Pharmacol. 2009, 77, 937-946. [CrossRef] [PubMed]

Publisher's Note: MDPI stays neutral with regard to jurisdictional claims in published maps and institutional affiliations. 